This copy is authors' original pre-print version and may slightly differ from the official published version.

Full citation:

Belt, P., Harkonen, J., Mottonen, M., Kess, P. and Haapasalo, H. (2008)

'Improving the efficiency of verification and validation', International Journal of Services and Standards, Vol. 4, No. 2, pp. 150 - 166.

DOI: http://dx.doi.org/10.1504/IJSS.2008.01663

\title{
Improving the efficiency of verification and validation
}

\section{Pekka Belt* ${ }^{*}$ Janne Harkonen, Matti Mottonen, Pekka Kess \& Harri Haapasalo}

Department of Industrial Engineering and Management, University of Oulu, Finland, P.O. Box 4610,

FI-90014 University of Oulu, Finland

E-mail: firstname.lastname@oulu.fi

*Corresponding author

\begin{abstract}
The application of electronics and software technologies is spreading to new areas, because they offer new feature possibilities. Consequently, these technologies require more validation and verification $(\mathrm{V} \& \mathrm{~V})$ efforts, resulting in increased costs and slower time-to-market for new products. The ICT industry has been forced to significantly improve its $\mathrm{V} \& \mathrm{~V}$ processes. In this study, major Scandinavian telecom companies have been interviewed to clarify the challenges of $\mathrm{V} \& \mathrm{~V}$, and to identify ways to tackle them. The management of traditional industrial sectors could use the experiences from the ICT sector as a benchmark, as the same challenges are to be faced by them.
\end{abstract}

Keywords: verification, validation, testing, management of testing, services, standards. 


\section{Introduction}

Software and electronics industries have changed and witnessed a transformation in terms of frequent technology changes, increase in complexity, time-to-market pressures and the decrease in physical dimensions. These factors have set enormous challenges for design, manufacturing, maintenance and procurement, which are unmatched by the challenges of any other industry. It has been claimed that it is impossible to design and manufacture products without defects (e.g. Woodward and Hennell, 2005; Black, 2004).

Modern high technology products with many features are getting increasingly complicated, especially in telecommunications industry. Rumney (2003) states that "the more complex a system becomes, the more resources are required to test it, but clearly from the perspective of the entire telecommunications industry, the growing complexity and cost of test can only be considered as painful". Test complexity can be interpreted as costs. The significance of testing activities is not commonly understood. In the literature, testing activities have been estimated to take between 30 to 80 percent of the entire costs in high-technology product development. Testing has become a critical factor (e.g. Kung et al., 1998; Gilb, 2005; Andersson and Runeson, 2002).

The terminology used in this article includes concepts of verification, validation and testing. Verification is widely understood as a method to prove the compliance with the specifications. The aim of validation is to prove that the user is satisfied. The term 'testing' is understood, in this article, broadly to cover both verification and validation.

This study examines testing from the management perspective, and it gives a basic description on testing in the Information and Communications Technology (ICT) sector. It might be useful for the management of other sectors to do benchmarking and learn from the ICT sector. In the beginning of the theoretical section, testing in relation to pure electronics hardware (HW), pure software (SW) and embedded SW \& HW cases are discussed. The empirical research examines the main sources of test costs in different phases of the product development process and presents the methods the case interviewees view as possibilities to be used to reduce these costs. The objectives of this study can be divided into three research questions:

$R Q 1$ How have the test methods developed in relation to electronics $H W, S W$ and embedded practices?

$R Q 2$ What are the current challenges of testing?

$R Q 3$ How can the efficiency and effectiveness of testing be improved?

\section{Development of testing activities}

\subsection{Testing in electronics development}

The size of electronic components has been reducing based on the well-known Moore's law (Moore, 1998; Moore, 1965), while the number of components within the products has increased making the testing issues and the management of components challenging. Products, especially in telecommunications, have an increasing number of features and customers have been spoiled with this variety, creating another aspect for testing issues. The power consumption through the number of different components has set requirements for batteries and has caused thermal challenges. Especially the wireless 
applications have had high frequency elements creating difficult to control phenomena that are complicated to model mathematically (Goh et al., 2006). These phenomena are difficult to simulate creating need for practical experimenting ( $\mathrm{Li}$ and Kececioglu, 2006). This all, added with problematic chains in relation to product development, in-house production, outsourcing, and suppliers (e.g. Cheng et al., 2007), with uncertainties over the responsibilities over testing activities. The physical object is generally tested at component, board, and system level. Therefore, HW testing can be seen as an issue with multiple dimensions.

There are different ways to ease the problems that arise through complexity, such as DFT (design for testability) (Abramovici et al., 1990), BIST (Built in self test) (e.g. Abramovici et al., 1990; Gizopoulos, 2006), embedded testing (Gizopoulos, 2006), or modularity (e.g. Gershenson et al., 2003). Modularisation shifts testing to earlier phases, when testing is considered in a scope of the entire product, and allows product variants and a degree of flexibility. Simulation on its behalf allows anticipating possible issues early (O'Flynn et al., 2007). Additionally, the choice of materials, techniques, components, and architecture are the keys for designing a desired product in electronics. Nevertheless, once the desired product has been created by using a set of components, another challenge for testing activities is to manufacture the products, even with a reasonable level of component variation. Products using sourced components must be tuned to obtain an ideal end result, or accept some of the tradeoffs. The variation is more of an issue for manufacturing and for sourcing the components than it is for development, but should be taken into account already during the New Product Development (NPD) phase.

\subsection{Testing in software development}

The global competition, with external demands of greater functionality and rapid delivery, sets severe time-to-market pressures for software development, having a profound impact on product design, construction, and testing, among others (e.g. Hersleb and Moitra, 2001). The differences between large and small companies make testing in software development even more complicated, as the large companies tend to emphasise documentation and the small ones lean on key persons on their procedures (Andersson and Runeson, 2002).

The cost of fixing errors increases towards the field use, where the costs can be up to 1000 times higher than in the requirements phase (Boehm, 1981), which could just be fatal for a business, considering the size of some of today's development projects. Changes in requirements, which are often made late in the development, cause a need to repeat testing, which is a waste of resources. Testing activities consuming a large proportion of resources and the late involvement of these activities in development (Perttula, 2007) causes significant risks for the businesses.

While there have been problems with the quality of the software, there have been different wisdoms and approaches at different times, to aid in rectifying these issues, formal methods in the 1980s, software process improvement in the 1990s, and yet something else for the current decade (Whittaker and Voas, 2002; Tsai, 2005). There are different approaches to decreasing the risks and minimising the spent resources in software development (e.g. Dey et al., 2007). Some, trying to "design out" the risks and costs, which requires "getting it right the first time". In reality, people make mistakes, and the specifications may be incorrect and are likely to change during the development. On the other hand, modularity could ease some of the complexity related issues and allow developing product variants quickly (Boehm and Sullivan, 2000), possibly shifting a few of the problems to the integration interface. Also, paying attention to the software 
architecture could be one of these approaches for decreasing risks. Another contemporary topic for addressing issues in development is SW test automation.

Software development models can provide a framework for development activities at different levels, but practically these models (V \& W Models, and others) see testing mainly as an error correction activity conducted at the end of the design cycle, as many SW development models, indicate (see for example, Mooz et al., 2003). Nevertheless, different NPD philosophies (e.g. Hsieh and Chen, 2005), for example positioning development activities so that they leave options open for changing situations, or categorising development activities (Perttula, 2007). This could also alleviate the current problems. After all, it is difficult to replace software testing, as changes in the processes merely transform testing activities into a new form. Instead, deliberately converting testing from a set of retrospective activities into an active flow alongside development could allow meeting the business requirements better.

The new process models for software development emphasise iterativity, incrementality and agility (Larman \& Basili 2003). As examples of these process models can be mentioned RAD (Rapid Application Development), RUP (Rational Unified Process), FDD (Feature Driven Development) and Scrum. In all of these models, the importance of checking and testing, and the way they are performed has changed compared to the traditional waterfall model. There are also new issues emerging in testing of software-based products over the entire product life-cycle, making testing more challenging than before. These issues include test automation, testing in product families, recognition of repair responsibility (root cause analysis) in long supply chains, and collection of relevant measurement data from the development process.

A simple rule of agile, of fixing every defect as soon as it is discovered, has several advantages which help to avoid ballooning of the problems. Not only do the defects take far les time to fix in agile approach, but also the development time will be faster due to clean and stable software code (Talby et al., 2006). This way, having to prioritise defects is avoided, easing the bottlenecks. Also, situations where the test priority issues are negotiated with customers will be avoided. Agile development techniques include the testers becoming fully integrated members of the development team (e.g. Talby et al. 2006; Juristo et al., 2006).

Management viewpoint on software testing has been tried to implement through process improvement. Process improvement models, such as maturity models, for instance capability maturity model integration (CMMI) (e.g. Lee and Chang, 2006; Ahern et al. 2004) or its testing derivates (e.g. Tiku et al., 2007; Burnstein, 1996) for process improvement, may oversimplify and transform challenges into management problems in a non-ideal manner, while the floor level does not understand the concept, or know its existence (Whittaker and Voas, 2002). CMM (Capability Maturity Model) might be a powerful tool for managing testing activities and practices, with its five levels of testing, ad hoc, repeatable, defined, managed and optimised (Boehm and Turner, 2003). However, this type of framework should not be taken too literally, but as guidance.

\subsection{Testing of systems with HW and SW integrated}

Considering HW and SW together, the significance and the challenges of verification and validation activities have been noted (e.g. Perttula, 2007; Maatta et al., 2007), but is yet to be discussed more extensively. The design, verification and testability are among the main challenges of the telecommunications industry, including both electronics HW and SW (Neuvo, 2004). Good testability design means more work in software and hardware development. If all test needs over the life-cycle were seen together, there would be better possibilities to find also financial justification for the increased R\&D work. 
Literature talks about embedded systems, which means that the code is stored with the system, typically without hard discs, where adding additional code dynamically is often an exception (e.g. Marwedel, 2006). Generally, the literature considers testing as a function conducted by a separate team after the development. According to Karlesky et al. (2006) practices similar to methodologies for software development, for managing the risks and producing quality software, have not yet become prevalent for embedded systems.

The literature also uses terms 'co-design' and 'co-synthesis', when discussing designing HW and SW together. This appears in the context of system design (e.g. De Micheli and Ernst, 2001; Broy, 2006). Co-design addresses the issue of designing software, and hardware on which the software runs, aimed at gaining some benefits when designing complex systems. This method is created to support concurrent design of HW and SW (e.g. De Micheli and Ernst, 2001), but has not been created from the testing perspective. Verification is a critical step in this methodology, while if SW and HW component design are not properly coordinated, it is quite likely that serious problems in the interface will be found too late (De Micheli and Ernst, 2001).

The organisational boundaries are one of the main barriers limiting the development of efficient processes (e.g. Maatta et al. 2007). The development of communication and information management practices presents a challenge, but when applied effectively they would provide an effective tool to keep on track with respect to goals and objectives of testing. Jablokow and Booth (2006) have noted how communication between separate stages provides a distinct business advantage by bringing together the diverse cognitive attributes necessary to solve the complex problems in high performance organisations. On the other hand, Patrashkova and McComb (2004) appreciate that highly qualified people may compensate for less overall communication, and that performance improves when the focus is on exchanging only the requisite pieces of information.

One interesting tool for managing and developing testing activities over the entire product development chain is the Lifetime Testability V model (LTV model) introduced by Antila (2006). The LTV model is a procedure for managing the testability requirements of a complex system. It also helps to identify any re-use possibilities for tests and test solutions over the product lifetime. Quite often different test methods have been developed to be used for a variety of products. Standardisation can reduce the amount of overlapping work, but can also have an enormous impact on the definition of products life (e.g. Kumar and Fullenkamp, 2005).

A problem with most test specific maturity models is that they are software engineering specific. TMM (Test Maturity Model) developed by Burstein (1996) is probably the oldest model for test management. Based on TMM, Ham et al (2001) have developed V2M2 (Verification and Validation Maturity Model), that is seen to be a comprehensive and thorough test process improvement model and yet it is not geared towards a specific type of business, such as software engineering. According to Maatta et al. (2007) V2M2 is seen as the best model for the management of testing activities.

\subsection{Analysis and implications of the literature review}

The telecommunications industry was originally a HW oriented field. This has changed and the share of SW has been increasing constantly. For instance, in telecommunications, the number of SW designers outnumbered the HW designers during the 1990s. Additionally, HW and SW have become more interrelated, which is generally discussed as embedded systems. Nevertheless, HW and SW being equally important, it is the software that really defines the functionality and may now be seen as more dominating. 
In the Figure 1, the development of testing methods is described as a function of time. The magnitude of testing is especially large in SW development. This is where SW developers first discovered that old, HW related, testing practices did not fit in with expanding testing needs. New practices had to be developed. The same challenges discovered in the SW industry have later emerged in HW as well. E.g. Karlesky et al. (2006) and Perttula (2007) claim that testing methods that were originally developed for SW can be applied for hardware as well.

The application of the ICT technologies is now spreading to other industries, for example to the automotive industry. Increasing complexity of products and growing need for integration result in challenges for testing. Sectors that have earlier been considered as solid "quality sectors" are now facing new problems with reliability. The management of these more traditional sectors has found it difficult to leave the old sector-specific mindset and learn from the SW and ICT sectors. The most developed testing practices can be found in SW and benchmarking could be beneficial. 
Figure 1 Development of testing activities

Other sectors

Embedded HW \& SW

Software

Hardware

\begin{tabular}{|c|c|c|c|}
\hline & \multirow{4}{*}{$\begin{array}{l}\text { HW based test methods did not } \\
\text { function in SW development. } \\
\text { New methods had to be } \\
\text { developed: } \\
\text { "Waterfall model } \\
\text { *V \& W models etc } \\
\text { *Modularity } \\
\text { *SW test automation } \\
\text { *Categorising development } \\
\text { activities \& testing } \\
\text { *Iteratively, incrementality and } \\
\text { agility } \\
\text { *Product families } \\
\text { *Root cause analysis } \\
\text { *SW specific process } \\
\text { improvement models (maturity } \\
\text { models etc.) }\end{array}$} & \multirow{4}{*}{$\begin{array}{l}\text { Also HW products get more } \\
\text { complicated and HW \&SW } \\
\text { become embedded. New test } \\
\text { methods must be adopted from } \\
\text { SW practices } \\
\text { "co-design \& co-synthesis } \\
\text { "Advanced systems models, } \\
\text { such as "Lifetime Testability V } \\
\text { model" } \\
\text { "Standarsation of products and } \\
\text { test methods } \\
\text { "General process improvement } \\
\text { models (i.e. V2M2) } \\
\text { "DTT } \\
\text { "BIST } \\
\text { "simulation }\end{array}$} & \multirow{3}{*}{$\begin{array}{l}\text { Testing problems will } \\
\text { spread also to other } \\
\text { sectors, which must } \\
\text { adopt current SW \& } \\
\text { HW practices and new } \\
\text { practices must be } \\
\text { developed }\end{array}$} \\
\hline & & & \\
\hline $\begin{array}{l}\mathrm{HW} \text { based } \\
\text { test } \\
\text { management }\end{array}$ & & & \\
\hline & & & \\
\hline
\end{tabular}

\section{Empirical study}

\subsection{The research process}

The empirical study was conducted to obtain an understanding on the main challenges of testing. The study covered the distribution of these costs and the interviewees' views on possible means of improving the productivity of testing through the entire product development process, including applied research, product development, production and after-sales. The study concentrated in examining companies within the telecommunication industry.

The empirical study consisted of 22 interviews, comprising a representation from different phases of the product development process. Each interview session was based on the same questionnaire (Appendix A). Nevertheless, interviews were conducted informally allowing the interviewees to explain and clarify the cases and topics as entities.

All the interviewed companies are involved in the ICT industry and most of them in telecommunications. Two of the companies are globally among the top companies in wireless communication. Other companies represented were a mid-sized European SW and HW business, providing solutions for wireless and automotive industries; a private Scandinavian distributor and supporter of wireless communication products and solutions; a small national business that reprocesses electrical and electronic products; a European electronics manufacturer (leader in its own field); and a mid-sized Scandinavian company specialising in electronics R\&D (with no production).

The companies that participated in the interviews can be divided into four categories (See Figure 2): The first company type is the 'gadget' manufacturers that sell their 
products globally. These companies provide products for both business-to-customer and for business-to-business markets. The second type of companies can be seen as subcontractors, whose products are inputs into the first category. The third category is companies who provide comprehensive test services, including test equipment, knowhow and consulting services. The fourth category comprises of companies developing and selling test equipment, which can be used to solve testing problems in high technology product development, manufacturing and after-sales. Therefore, these interviews represent the $\mathrm{V} \& \mathrm{~V}$ activities in a versatile manner and provide understanding over managing diverse issues.

Figure 2 The distribution of different company categories within the development chain

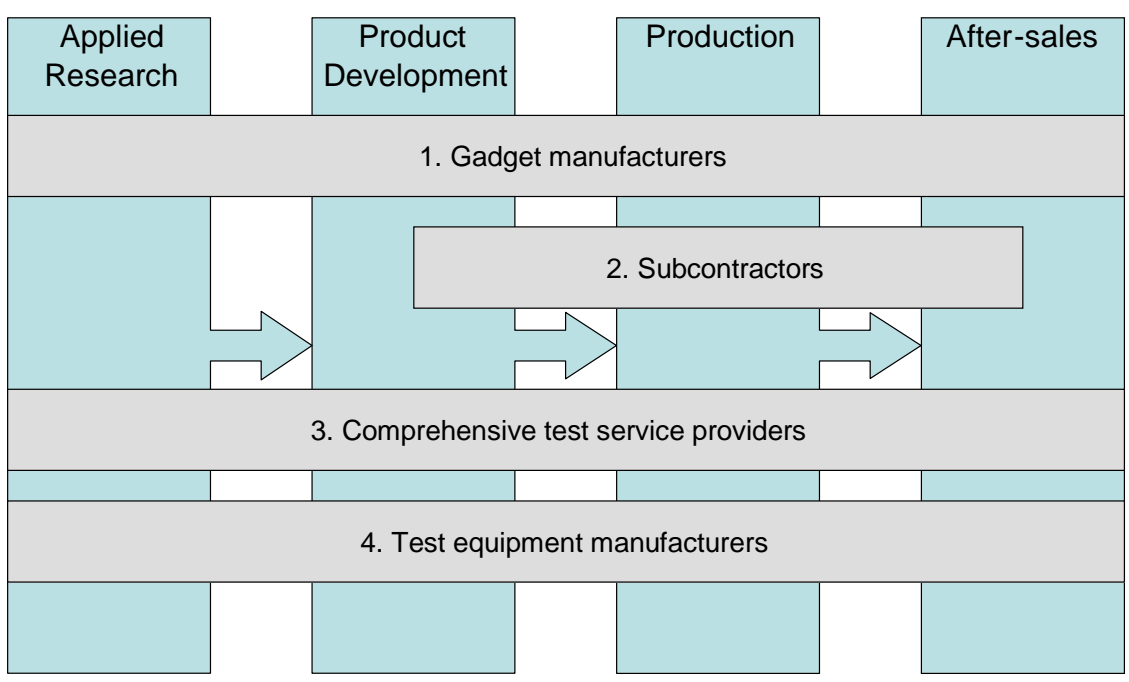

The participants interviewed were selected carefully on the basis of their professional background and expertise. Selected participants hold responsible positions in the field of testing. The experience and the current interests ensured the high motivation among the participants and up-to-date knowledge with respect to the discussed topics. The people interviewed had experience either in both Hardware and Software testing, or in one of these. The total work experience of the interviewed was typically between 10 and 20 years, out of which they have spent a significant part with testing activities, but have also held other positions. The job titles of the respondents include: Quality Manager, Quality Controller, Competence Area Manager, Senior Test Manager, Product Development Manager, Director (R\&D), Engineering Manager, Manager (After-Sales), Group Manager, and Senior Developer. The selected participants were among the topprofessionals in the field of testing.

\subsection{Results of the interviews}

\subsubsection{Applied research}

In the applied research phase the benefits of testing are seen as being unclear as it is not certain whether the efforts are on the right technology, or not. The equipment required in 
the phase is seen as expensive and to have a relatively short life-span. The case interviewees saw testing competences during the applied research phase to be typically quite poor, and that test costs could potentially be reduced by developing test related competences of the personnel.

Reviews and systematic management are seen as the key for identifying potential sources for cost savings. Other means that were brought up by the case interviewees included increased amount of simulations in order to avoid unnecessary numerous investments in expensive equipment.

Earlier cases are not seen to be used as examples because each case is considered as unique and because companies are lacking of systematic practices. On the other hand, too stringent procedures could limit the creativity needed in research.

\subsubsection{Product development}

In the product development the personnel costs are seen to dominate the overall costs. The product development phase needs a more versatile range of measurement equipment than is needed in the production phase. Nevertheless, the level of automation in product development is not seen as high as in the production phase. Software testing typically forms a large share of the total test costs in the product development. The productivity was seen to be potentially improved by reducing the amount of tests, removing overlapping between different phases, by developing the accuracy of test data systems and by increasing the personnel training on test related competences. Unreliability of new test systems is another problem that is seen important during the product development phase.

One of the interviewees stated that when developing embedded systems, it is common practice to first finalise the hardware. Once the hardware is frozen, there will be one factor less worry about, and the final functionality is achieved by software.

Test costs in the product development phase are higher than in any other phase. The level of testing competence is seen as the most critical factor which has a great impact on the economic success of the companies. It is seen to be very expensive to develop automatic software testers. However, should the volumes be high, they could be worth the investment.

\subsubsection{Production phase}

In the production phase the test costs are seen to have even bigger role in some cases compared to the actual production costs. The investments required in the equipment for production testing are seen to be of especially large scale. Creating test environments requires competent personnel and capital resources (investments in equipment, computer networks etc.). Testing is seen to require enormous amount of time, if the previous phases, including the product development phase, have not found proper solutions.

In the production phase testing can be divided into two categories, process testing and functional testing. It was seen important to have a gradual shift from functional testing towards process testing, as the functional testing is experienced as time-consuming and expensive. The main motivation for this is the fact that should there be less functional testing and an increased amount of process testing the same test equipment could be used for several products. Also, finding the fault sources is seen more difficult with functional testing. Therefore, functional testing should be made more flexible, and its costs should be decreased via optimisation, by reducing any unnecessary tests.

The test costs were seen to be reduced by removing overlapping tests with previous phases. Additionally, sampling and test categorisation could be useful tools for reducing 
the number of tests. These were all seen as potential actions. However, according to the case interviewees they must be executed without sacrificing the product quality.

It is seen important to have systematic testing procedures in the production phase, as it would be extremely costly if a service person was to be sent to the customer's location to fix a problem. There can even be a risk of losing customers, should the caused inconvenience be overwhelming.

Software is not usually tested at all in the production phase.

\subsubsection{After-sales}

Even the after-sales phase requires a surprisingly large number of test equipment constituting the biggest cost factor for the entire after-sales phase. According to an interviewee, about $40 \%$ of the costs in the after-sales come from personnel costs and the rest comes from material and equipment. Basic maintenance work in after-sales means finding the nature of the failure and fixing it by using subcontracted operators. If the service and the maintenance function are distributed to a number of locations, the number of equipment will be multiplied equally. On the other hand, the greater number of equipment makes it possible to develop them cheaper, including required software solutions. A centralised function is seen to cause great transportation costs. Therefore, cheaper equipment is seen as a possible means of justifying an increase in the number of test units located locally to the customer. In the after-sales phase the testing costs are seen to be minimised the best by product standardisation.

\subsubsection{The costs of testing}

The testing costs can roughly be grouped into two categories, i.e. equipment and people. When test equipment investments are considered there is a comparison between purchase costs and gainable personnel cost savings. Investments are one-time costs by nature, but the amount of money needed is typically large. Measurement equipment needed are numerous, and typically very expensive, prices ranging from a few thousand euros to $50000 €$ (the price of a general measurement device). Specialised equipment can cost even more. Nevertheless, the life-cycle of the test equipment is usually short.

Off-the-shelf testing packages are not always available, so there is a need to analyse whether the testing systems and other tools must be developed in-house or bought from outside. In-house development requires additional resources for any maintenance activities. Should the equipment be purchased from outside, the supplier takes care of the maintenance. When testing equipment is developed in-house, the test methods are simultaneously developed. Developing test methods must be taken into account at the stage, when the investment decisions are made.

When investment decisions are considered, also training personnel must be included, as testing competence is a crucial factor. Training is, however, expensive and it is therefore seen as one of the most significant cost factors. Also, the calibration of devices causes considerable costs. Quite often the measurement equipment and the required software must be planned and developed case specifically. An example of a relatively common problem causing costs is the inaccuracy of test equipment that results in phantom defects, i.e. there is nothing wrong with the actual product, but the fault is in the system used for testing.

Table 1 summarises the factors, highlighted by the case interviewees, which must be taken into account when considering investments in testing. 
Table 1 Factors influencing test investments

\begin{tabular}{ll}
\hline Test equipment & Personnel costs \\
\hline Purchase or in-house development & Salaries \& over-heads \\
Maintenance & Training \\
Calibration costs & \\
Life-cycle of the test equipment & \\
Test method development & \\
\hline
\end{tabular}

\subsubsection{How to improve the efficiency and effectiveness of testing?}

The productivity of testing is not seen to necessarily improve, even with higher investments, unless the amount of testing is reduced somehow. Improving the productivity starts with understanding the value chain itself. The earlier the faults are found, the cheaper they are to rectify. In addition, testing activities for the following phases should be considered in a proactive manner, so that each individual phase would consider the requirements of the internal customers as well. A sufficient test management system should be developed and it should describe the reached test coverage after each test phase. System Failure Mode and Effect Analysis (SFMEA) is viewed as a potential way of controlling the test process.

The development of communication and information flow between different phases is seen to have a vital role in improving the efficiency of testing activities over the entire product development process.

The productivity of testing is improved by removing any overlapping tests. The same tests should be performed only once. The removal of overlapping should be conducted without risking the test coverage. Companies should invest in planning the testing activities prior to conducting them. Developing products that require less testing would also reduce costs.

The productivity is potentially seen to be improved with an appropriate balance between the number of test personnel and product developers, in the product development phase. Currently there is a deficit of testing personnel. The development of the test related competences of personnel is seen of great importance, as the case interviews indicated that there is a lack of competent personnel in every phase of the development chain.

Another way to improve productivity is to standardise the interfaces between different products, to enable testing different products with the same test equipment and with the same methods. The same testers and test methods could be used even though the tests are virtually different. The inaccuracy of the measuring equipment is a potential problem. Testing could be more effective if the accuracy was to be improved, or there would be methods to take the inaccuracy of measurement into account.

The test equipment are expensive and their life-time is short, therefore, the utilisation of the test equipment should be maximised. The existing equipment base should also be used in different projects. Competent people need excellent equipment to achieve good results. Also, leasing test equipment should be considered as an alternative to actual purchase.

The burden of testing experienced during the product development phase can be eased by methods such as simulation and synchronisation of software and hardware subprojects, and also by utilising the knowledge gained during previous projects. 
The productivity could also be improved by developing and better utilising test automation, especially in software testing. However, automating everything is not reasonable for the companies, as there are so many different products that are produced. According to an interviewee, the amount of conveyor belts and other automatic partmoving equipment have already been diminished and currently an increasing amount of part-moving is performed manually by personnel. This has made the production more flexible and profitable.

The actual act of testing is often automatic, resulting with the understanding of whether the product is functioning as planned or not. However, the exact reason, or location of the fault is not usually known immediately, but requires analysis by competent personnel.

The case interviewees saw several ways to develop functional testing. Functional testing should be developed cheaper and quicker for example by using BIST (Built In Self Test) or embedded testing. Test methods based on sampling should be developed and it should also be made possible to optimise the amount of process and functional testing for every product.

Case interviewees pointed out that quite often the mind-set of the management has not followed the development, but rather continues the old paradigms. This makes the adaptation to changing environments more difficult. As an example the senior management of the telecommunication sector has considered the sector hardware business, although the number of software engineers outnumbered the hardware ones already during 1990s. Equally, the top management of the automobile sector is fixed to the old mind-sets and has difficulties to see that it might be worthwhile to learn form the software business as the share of electronics and software in cars has increased significantly during the recent years.

Table 2 summarises the interviews. It presents the challenges/problems and solutions to make testing more effective in each phase of product process. 
Table 2 Challenges/Problems \& Possible solutions to make testing more effective

\begin{tabular}{|c|c|c|}
\hline Phase & Challenges/Problems & Solutions \\
\hline \multirow[t]{3}{*}{ Applied research } & $\begin{array}{l}\text { *Uncertainty on what to } \\
\text { research }\end{array}$ & *Simulation \\
\hline & *Lack of competent personnel & \\
\hline & *Lack of systematic practices & \\
\hline \multirow[t]{5}{*}{ Product development } & *High personnel costs & $\begin{array}{l}* \text { Balancing the number of designers } \\
\text { and test personnel }\end{array}$ \\
\hline & *Lack of competent personnel & *Personnel training \\
\hline & *Large amount of tests & $\begin{array}{l}* \text { Test automation especially on } \\
\text { software testing }\end{array}$ \\
\hline & *Overlapping tests & \\
\hline & $\begin{array}{l}\text { *Unreliability of new test } \\
\text { systems }\end{array}$ & \\
\hline \multirow[t]{5}{*}{ Production } & $\begin{array}{l}\text { *High investment costs \& } \\
\text { short life-time of equipment }\end{array}$ & *Avoid overlapping tests with $\mathrm{R} \& \mathrm{D}$ \\
\hline & *Lack of competent personnel & $\begin{array}{l}\text { *Developing tests methods of } \\
\text { functional testing (e.g. sampling) }\end{array}$ \\
\hline & $\begin{array}{l}\text { *Functional testing is } \\
\text { expensive \& bottleneck }\end{array}$ & *Removal of unnecessary tests \\
\hline & *Large amount of tests & $\begin{array}{l}\text { *Emphasis shift from functional to } \\
\text { process testing }\end{array}$ \\
\hline & *Inaccuracy of test equipment & \\
\hline \multirow[t]{2}{*}{ After Sales } & $\begin{array}{l}\text { *Large number of test } \\
\text { equipment }\end{array}$ & \\
\hline & *Non-standardised products & \\
\hline \multirow[t]{6}{*}{ Entire development chain } & $\begin{array}{l}\text { *Overlapping tests between } \\
\text { different phases }\end{array}$ & *Understanding the entire value chain \\
\hline & $\begin{array}{l}\text { *Lack of understanding the } \\
\text { entire chain }\end{array}$ & $\begin{array}{l}\text { *Shifting the emphasis to earlier } \\
\text { stages }\end{array}$ \\
\hline & & $\begin{array}{l}\text { *Each phase should consider the } \\
\text { following phase }\end{array}$ \\
\hline & & $\begin{array}{l}\text { *Utilisation of test management } \\
\text { systems to control test coverage and } \\
\text { eliminate overlapping }\end{array}$ \\
\hline & & *Standardisation of product interfaces \\
\hline & & $\begin{array}{l}\text { *Maximised utilisation of test } \\
\text { equipment }\end{array}$ \\
\hline
\end{tabular}


*Better synchronisation of HW \& SW projects

*Better utilisation of the experiences of earlier projects

*Increasing Embedded testing \& BIST

\section{Managerial implications to services and standards}

Testing has become a very important factor in producing ICT products, and is responsible for a significant part of the overall costs. Testing should be understood as an internal service function supporting the development and production of high quality products. Testing is not an end in itself, but rather a part of a bigger goal. In order to make this internal service function as efficient as possible, it must be integrated into the company strategy and into the entire product development process.

To reduce costs and to shorten the development cycles testing must be optimised. The optimisation must start with consideration of the entire development chain, and continue through every phase of the NPD to minimise the overlapping. Internal cooperation is needed between different phases and functions. Testing is a challenging service function requiring versatile knowledge and competences e.g. on test methods, product structure and purpose, specifications, and technological limitations. SW testing is a forerunner in the development of testing activities and management practices.

One way of rationalising testing is to outsource it. Testing services are, however, still underdeveloped, but specialised testing services are likely to increase in the future, and outsourcing testing should be an option to device manufactures.

When formulating their research strategies companies should connect their researchers to the standardisation work as technologies and products are later tested against these standards. During the product development phase the interfaces between various modules should be standardised to make it easier to use the same testing methods.

\section{Conclusion}

Testing activities are typically not been managed sufficiently as an independent set of actions. Sub-optimising testing activities can cause inefficiency and repetition of tests. Regardless of the efforts for making each phase more efficient is obviously worth striving for, the best results are obtained by analysing the entire testing chain as a whole. The study indicated how better results can be obtained by closer integration of hardware and software elements. A general learning is that the emphasis of testing activities should be shifted towards earlier phases. Each phase should consider not only testing within the own phase but also the following phases as well in order to remove unnecessary overlapping. Product development should include the planning of testing activities for the whole chain. One common problem identified in this study is a general lack of personnel with good and versatile competences in testing. Also systematic management practices are in a key position in improving the efficiency of test activities (rq2 \& rq3).

The application of the ICT technologies is now spreading to other industries. The management of more traditional sectors can learn from the experiences of the ICT sector that has a strong cumulative experience on how to cope with the testing burden. The most 
developed testing practices can be found in software development, which is currently the pinnacle of testing technology (rq1).

The management of testing activities requires further research e.g. on how to shift the emphasis of testing to earlier phases of product development and how to enhance the communication between these phases.

The number of case interviews was not especially extensive, thus by having a wider set of organisations to be reviewed; the obtained results might have yielded a different analysis of contemporary testing activities within the telecommunication industry. The study was qualitative in nature and the aim was purely to obtain further knowledge and understanding of the discussed topics. Therefore, additional interviews would probably not provide significant added value for the scope of this study.

\section{References}

Abramovici, M., Breuer, M. A. and Friedman, A. D. (1990) 'Digital systems testing and testable design’, Computer Science Press, NY, pp. 653. ISBN 0-7167-8179-4

Ahern D. M., Clouse A. and Turner R. (2004) 'CMMI Distilled, a Practical Introduction to Integrated Process Improvement', 2nd edition, Addison-Wesley, ISBN 0-321-18613-3.

Andersson, C. and Runeson, P. (2002) 'Verification and validation in industry - a qualitative survey on the state of practice', Empirical Software Engineering, Proceedings, IEEE, International Symposium.

Antila, J. (2006). 'Lifetime Testability V-model'. EBTW'06 European Board Test Workshop, Southampton, May 24-25, 2006.

Black, R., (2004) 'Critical testing process - Plan, Prepare, Perform, Perfect', Addison-Wesley, Boston.

Boehm, B. W. (1981) 'Software engineering economics'. Prentice Hall, pp. 767. ISBN 0-13822122-7.

Boehm, B. W. and Sullivan, K. J. (2000) 'Software economics: a roadmap', International Conference on Software Engineering, Proceedings of the Conference on The Future of Software Engineering, Limerick, Ireland, pp. 319-343.

Boehm, B. W. and Turner, R. (2003) 'Balancing Agility and Discipline: A Guide for the Perplexed', Addison-Wesley, pp. 160, ISBN 0-32118612-5.

Broy, M. (2006) 'Challenges in automotive software engineering', proceeding of the 28th international conference on Software engineering, ACM Press, NY, pp. 33-42.

Burnstein, I. (1996) 'Developing a Testing Maturity Model', Illinois Institute of Technology.

Cheng, S-R., Hsu, B-M. and Shu, M-H. (2007) 'Fuzzy testing and selecting better processes performance', Industrial Management and Data Systems, Vol. 107, No. 6, pp.862-881.

De Micheli, G. and Ernst, R. (2001) 'Readings in Hardware/Software Co-Design', Morgan Kaufmann, pp. 697, ISBN 1-5586-0702-1.

Dey, P. K., Kinch, J. and Ogunlana, S. O. (2007) 'Managing risk in software development projects: a case study', Industrial Management and Data Systems, Vol. 107, No. 2, pp.284-303.

Gershenson, J. K., Prasad, G. J. and Zhang, Y. (2003) 'Product modularity: definitions and benefits', Journal of Engineering Design, Vol. 14, No. 3, pp. 295-313.

Gilb, T. (2005) 'Competitive Engineering: A Handbook for Systems Engineering, Requirements Engineering, and Software Engineering Using Planguage', pp. 480.

Gizopoulos, D. (2006) 'Advances in Electronic Testing: Challenges and Methodologies', Springer, pp. 412.

Goh, T. J., Chiu, C-P., Seetharamu, K. N., Quadir, G. A. and Zainal, Z.A. (2006) 'Test chip and substrate design for flip chip microelectronic package thermal measurements', Microelectronics International, Vol. 23, No. 2, pp.3-10. 
Ham, M., Jacobs, J., Swinkels, R., and Van Veenendaal, E. (2001). 'Metric Based Testing Maturity Model Framework v1.1', [Available online], <http://tmitwww.tm.tue.nl/research/v2m2/>, Read 22.11.2004.

Hersleb, J. D. and Moitra, D. (2001) 'Global software development', IEEE, Software, Vol. 18, No. 2, pp. 16-20.

Hsieh, L-F. and Chen S. K. (2005) 'Incorporating voice of the consumer: does it really work?', Industrial Management and Data Systems, Vol. 105, No. 6, pp.769-785.

Jablokow, K. W. and Booth, D. E. (2006) 'The impact and management of cognitive gap in high performance product development organizations', Journal of Engineering and Technology Management, Volume 23, Issue 4, pp. 313-336.

Juristo, N., Moreno, A. M. and Strigel, W. (2006) 'Software Testing Practices in Industry', Software, IEEE, Vol. 23, No. 4, pp.19-21.

Karlesky, M.J., Bereza, W.I. and Erickson, C.B. (2006) 'Effective Test Driven Development for Embedded Software', Electro/information Technology, IEEE, pp.382-387.

Kung, D.C., Hsia, P. and Gao, J. (1998) 'Testing object-oriented software', IEEE Computer Society Press, pp.280.

Kumar, S. and Fullenkamp, J. (2005) 'Analysis of European Union environmental directives and producer responsibility requirements', International Journal of Services and Standards, Vol. 1, No. 3, pp. 379-398.

Larman, C. and Basili, V.R. (2003) 'Iterative and incremental developments. a brief history', IEEE Computer, Vol. 36, No. 6, pp.47-56.

Lee, M-C. and Chang, T. (2006) 'Applying TQM, CMM and ISO 9001 in Knowledge Management for software development process improvement', International Journal of Services and Standards, Vol. 2, No. 1, pp. 101-115.

Li, Q. and Kececioglu, D. B. (2006) 'Design of an optimal plan for an accelerated degradation test: a case study', International Journal of Quality and Reliability Management, Vol. 23, No. 4, pp.426-440.

Maatta, J., Jokinen, T., Haapasalo, H., Mottonen, M., Belt, P., Muhos, M. and Harkonen, J. (2007) 'How to enhance the efficiency of testing - Management viewpoint?' [Accepted to Journal of Engineering and Technology Management, publication pending]

Marwedel, P. (2006) 'Embedded System Design', Springer, pp.236, ISBN 0-3872-9237-3.

Moore, G. E. (1965) 'Cramming more components onto integrated circuits', Electronics Magazine 19 April

Moore, G. E. (1998) 'Cramming More Components onto Integrated Circuits', Proceedings of the IEEE, Vol. 86, No. 1, pp. 82-85.

Mooz, H., Forsberg, K. and Cotterman, H. (2003) 'Communicating project management: the integrated vocabulary of project management and systems engineering'. John Wiley \& Sons Inc., ISBN 0-471-26924-7.

Neuvo, Y. (2004) 'Cellular phones as embedded systems', Solid-State Circuits Conference, Digest of Technical Papers. ISSCC. IEEE International, 15-19 February, pp. 32-37.

O'Flynn, B., Laffey, D., Buckley, J., Barton, J. and O'Mathuna, S. C. (2007) 'Simulation, design, development and test of antennas for wireless sensor network systems', Microelectronics International, Vol. 24, No. 2, pp.3-6.

Perttula, A. (2007) 'Challenges and Improvements of Verification and Validation Activities in High Volume Electronics Product Development', $\mathrm{PhD}$ dissertation, Tampere University of Technology, Finland. Publication 650.

Patrashkova, R. R. and McComb, S. A. (2004) 'Exploring why more communication is not better: insights from a computational model of cross-functional teams', Journal of Engineering and Technology Management, Vol. 21, No. 1-2, pp. 83-114.

Rumney, M. (2003) 'Position statement by panellist Moray Rumney of Agilent Technologies', International Test Conference, ITC 2003 Panel Discussion Testing 3G-controlled systems: 
time to rejoice or time to feel pain? [Available online] <http://csdl2.computer.org/comp/proceedings/itc/2003/2063/00/20631322.pdf>

Talby, D., Keren, A., Hazzan, O. and Dubinsky, Y. (2006) ' Agile software testing in a large-scale project', Software, IEEE, Vol. 23, No. 4, pp.30-37.

Tiku, S., Azarian, M. and Pecht, M. (2007) 'Using a reliability capability maturity model to benchmark electronics companies', International Journal of Quality \& Reliability Management, Vol. 24, No. 5, pp.547-563.

Tsai, B-Y. (2005) 'A novel hybrid object-oriented class testing method', International Journal of Services and Standards, Vol. 1, No. 4, pp. 512-524.

Whittaker J. A. and Voas J. M. (2002) '50 years of software: key principles for quality', IT Professional, Vol. 4, No. 6, pp. 28-35.

Woodward, M. R. and Hennell, M. A. (2005) 'Strategic benefits of software test management: a case study', Journal of Engineering and Technology Management, Vol. 22, No. 1-2, pp.113140 . 


\section{APPENDIX A}

\section{QUESTIONNAIRE}

\section{Background information:}

- Name of the Interviewee:

- Company:

- Turnover of the company:

- Number of employees:

- Number of employees working in NPD:

- Job title:

- When did the interviewee start in the current role:

- Previous work experience:

1. What phase of the development chain do you represent (research, product development, production, after-sales, whole chain)?

2. What type of activities do you consider as testing?

3. What is testing like in the phase you represent?

4. What type of investment in test equipment, software, know-how) does the phase require in your company?

5. What type of costs (man-hours, development, time, and cost of errors are caused by testing?

6. Can the expenses be decreased via any actions, e.g. investment?

7. What type of input would make the phase smoother?

8. What types of problems created in the previous phase arise here?

9. What type of actions could serve the following phase the best?

10. What are the testing bottlenecks of the phase?

11. What are the key competencies for testing?

12. Can the testing activities in the phase be purchased from outside, or be sold outside?

13. How can the testing activities be improved?

14. Other comments on testing activities

(The details of the interviewee or the company will not be disclosed in any published material.) 